Exploring the Meaning of Spirituality and Spiritual Care in Chinese Contexts: a Scoping Review

Page 1 of 25 


\begin{abstract}
Spirituality is recognised as a fundamental aspect of health and nursing care. Yet, there are few studies exploring how this concept may be understood outside of Western culture. This scoping review seeks to address this omission by focusing specifically on research conducted with Chinese populations. This is important because people from Chinese backgrounds (PBC) are now residing all over the world, and their spirituality and spiritual needs should be considered when providing healthcare. Adopting a purely generalist understanding and application of spirituality may not capture the cultural difference that exists between the East and West. This scoping review adopted Arksey and O'Malley's method to focus on spirituality and spiritual care among PBC in health and nursing. The systematic strategy was adopted and used to search the main databases in health and nursing. Eighteen $(n=18)$ empirical studies were included the review 11 qualitative studies and seven quantitative involving 1,870 participants.
\end{abstract}

The scoping review revealed that in the Chinese understanding of spirituality is an abstract and personal concept which can refer to an internal vital force, experiences of suffering, and traditional Chinese cultural and religious values. As the multidimensional understanding of spirituality and spiritual care my cause confusion, these findings may provide a direction for the researchers emphasising the need for cultural and religious sensitivity when understanding of spirituality.

Keywords: scoping review, health, nursing, spirituality, Chinese

\title{
Introduction
}

The International Council of Nurses (ICN, 2012) stresses the importance of responding to patients' spiritual beliefs when providing nursing care. In Western culture, spirituality and spiritual care in healthcare has been developed over many years, and the different definitions highlight that spirituality is a subjective and culture-orientated term (Cockell \& McSherry, 2012). However, in Chinese regional contexts, the meaning of spirituality and spiritual care are under developed, with limited themes (Chao, Chen, \& Yen, 2002) or processes (Chiu, 2000) and they are often described in terms of belief,

\section{Page $\mathbf{2}$ of $\mathbf{2 5}$}


relationships, and values. This review provides a comprehensive understanding of spirituality in the Chinese cultural context in order to inform culturally sensitive spiritual care for people from Chinese backgrounds.

Spiritual care is one of the four pillars of holistic care according to the World Health Organisation (WHO, 2013). It has been explored for several decades in nursing and healthcare (McSherry, 2007), and various definitions of spirituality have been developed that reflect or incorporate Western culture (Puchalski, Vitillo, Hull, \& Reller, 2014; Weathers, McCarthy, \& Coffey, 2015). The lack of consensus in defining spirituality demonstrates that it remains subjective with different meaning, depending on individual and cultural influences (Narayanasamy, 1993; Tanyi, 2002).

Researchers have recognised the importance of spirituality and spiritual care in Chinese contexts and have identified that it can be understood in terms of 'relationship' - an association with self, others, nature and Higher Being(s) (Chao et al., 2002). Some also refer to spirituality as developmental process from facing and accepting illness, to finding meaning in religious/cultural values (Chiu, 2000). Mok, Wong, and Wong (2010) suggested that it is establishing compassionate relationship with religious and life principles to attain transcendence through harmony with others and individual wholeness.

These Chinese concepts are less comprehensive than those in Western contexts, focusing specifically upon belief, relationship and values (Carson \& Stoll, 2009; Weathers et al., 2015). Moreover, the findings are derived from fewer investigations involving small numbers of nurses or patients in specific locations for example hospitals in Taiwan (Chao et al., 2002; Chiu, 2000) and Hong Kong (Mok et al., 2010) so it is not known whether they apply to a wider Chinese population, outside Taiwan and Hong Kong. This indicates the need to assimilate findings of studies from different Chinese cultural settings, to establish an understanding of spirituality and whether the term includes broader meanings.

\section{Page 3 of 25}




\section{The review methods}

The scoping review followed Arksey and O’Malley's (2005) and Colquhoun et al.'s (2014) staged methodological guidance. This met the guideline for PRISMA Extension for Scoping Reviews (PRISMA-ScR) (Tricco et al., 2018).

\section{Search methods}

A comprehensive search strategy (Table 1) was applied in the six main healthcare databases: Cumulative Index to Nursing and Allied Health Literature (CINAHL), Medical Literature Analysis and Retrieval System Online (MEDLINE), PsycINFO, Applied Social Sciences Index and Abstracts (ASSIA), ScienceDirect, and Web of Science. The search results from each database were exported to Endnote software to scan against the inclusion and exclusion criteria (Table 2). These criteria were negotiated and consensus reached among the authors.

\section{Quality appraisal}

The Critical Appraisal Skills Programme (2013) was used as the qualitative appraisal tool, following the rating criteria, and the National Institute for Health and Care Excellence (NICE, 2009) was the tool for reporting correlations and associations for quantitative studies. The selection and quality appraisal of the studies were initially conducted by one author and the consensus of appraisal was reached with the other two authors.

Nine of the qualitative studies (Chao et al., 2002; Chio et al., 2008; Chiu, 2000, 2001; Hsiao, Gau, Ingleton, Ryan, \& Shih, 2011; Lin, Ma, Chen, \& Chou, 2012; Mok et al., 2010; Shih et al., 2009; Yang, Narayanasamy, \& Chang, 2012) were assessed as high or good quality, while the other two were deemed as lower quality (Sum \& Leung, 2013; Wong \& Yau, 2010), as they failed to address the rigour of the research in sufficiently describing the process surrounding data analysis. In addition, their findings lacked adequate supporting evidence.

\section{Page 4 of 25}


The seven quantitative studies (Chan, 2010; Chan et al., 2006; Chung, Wong, \& Chan, 2007; Wong, Lee, \& Lee, 2008; Yang, 2006; Yang \& Wu, 2009; Yang \& Mao, 2007) were found to be weak against the NICE (2009) appraisal tool as it was developed primarily to assess association and correlation. This was achieved by applying strict criteria to evaluate the research method, outcome measurement and analysis method for the selection of the exposure/comparison group. The questionnaire designs in the included studies were unfit for the comparison criteria established in the NICE (2009) appraisal tool. The reason that NICE tool was chosen is because currently there are no appropriate appraisal tools for a questionnaire design study.

\section{Data abstraction}

The findings of themes or sub-themes from the 18 studies, together with supporting evidence, were transferred into the Joanna Briggs Institute (JBI) Qualitative Assessment and Review Instrument extraction form. The main points addressed within the quantitative study findings were also extracted along with supporting evidence. The extracted findings were sequenced numerically so they could be tracked in each study for accurate interpretation when regrouped in the analysis. Finally, they were imported into NVivo11 for basic data analysis and integration by freely moving similar findings (nodes in NVivo) into a higher-level group/node.

\section{Synthesis}

The qualitative and quantitative findings from the extracted studies were analysed and synthesised. Table 3 presents a sample of the extracted and synthesised data to facilitate discussion in this article. A full synthesis of the data from current literature is available in the primary researcher's thesis (Author, 2019). Qualitative findings with similar meaning (Level 1) were aggregated into eight categories (Level 2) 'Characteristics of spirituality', 'Internal force', 'A harmonious relationship', 'Suffering', 'Traditional Chinese cultural values', 'Religion', 'Ways of spiritual care' and 'Barriers and benefits of spiritual care'. These categories were further synthesised into two themes 'Meaning of spirituality' and 'Implementation

\section{Page 5 of $\mathbf{2 5}$}


of spiritual care', with the first six categories forming the former and the last two, the latter (JBI, 2011). In the same way, quantitative findings with similar meanings were assembled into one category 'Factors influencing spirituality and spiritual care', which was aggregated into the theme 'Implementation of spiritual care'.

\section{Results}

\section{Search outcomes}

A total of 5,621 studies were identified from inception to 30 June 2015. After the removal of duplicates and irrelevant articles, 399 international studies were retrieved, addressing perceptions of spirituality and spiritual care. Applying the key concept 'Chinese' led to the identification of 33 studies. These were assessed against the inclusion and exclusion criteria, retrieving 18 articles (Figure 1) and removing 15. The same search in December 2018 did not identify any additional articles meeting the inclusion criteria, conducted from 1 July 2015 to 1 December in 2018.

The 18 studies had been conducted between 2000 and 2013, with none published between 2014 and 2018 (Table 4). Fifteen studies had been carried out in Taiwan and Hong Kong, with two quantitative investigations in China and one qualitative study in the USA. Aggregation of the participants totalled 1,870 , broken down as 249 in the qualitative and 1,708 in the quantitative studies. All the studies contributed to an understanding of spirituality and spiritual care from nurses' or patients' perspectives.

\section{Themes}

The synthesis of qualitative and quantitative categories (JBI, 2014) led to the development of two major themes regarding perceptions of spirituality and spiritual care in Chinese contexts within the field of nursing: 'Meaning of spirituality' and 'Implementation of spiritual care'. These highlight the spiritual pursuit of people from Chinese backgrounds during their lifetime, especially during illness when spiritual care may be required.

\section{Page 6 of 25}




\section{Theme 1: Meaning of spirituality}

This theme comprises six categories and presents a general description of the term spirituality.

\section{Category 1: Characteristics of spirituality}

The term 'spirituality' is unique and personal. It is abstract and not easy to articulate, one participant highlighted (Mok et al., 2010),

"Spirituality has to be interpreted from a person's own personal perspective; it is how a person defines it, and can refer to one's soul or one's beliefs. It is in the mind and soul, which are internal feelings." p.364 (F110)

An inability to articulate the term was considered by Sum \& Leung (2013) as explaining why enrolled student nurses were unable to offer a definition of spirituality (F093).

\section{Category 2: Internal force}

PCB described spirituality as an internal force that provides them with vibrancy and energy. A participant in Lin et al.'s (2012) study stated that spirituality is a real, existing power, "I think spirituality is a sound in the heart, which is deepest in the heart. Very few people can realise it because it grows with the person. It is like organs, such as the liver, in our body; we cannot feel its existence. It exhibits when a person is weak, which a person probably cannot notice. A person needs to figure it out gradually. A person needs to pursue that power when he is in need and is unable to go forward. Correct, it is this power to make people live since they have it. It seems like people are attractive to each other because of spirituality." p.225 (F109)

This suggests that from a Chinese perspective, spirituality is an entity akin to an organ deep inside a person, and spirituality comes into focus during times of weakness, acting as a force to sustain life and provide motivation for people to overcome difficulty. It is a biological understanding, indicating that

\section{Page 7 of 25}


spirituality is a part of humans and the source of their life, personal and social relationships (Swinton, 2010).

Spirituality is also described by participants in Sum and Leung's (2013) study as an internal force originating from the inner being. These authors present the key concepts of spirituality as 'inner', 'spirituality', 'in heart' and 'core' (F091). Spirituality encourages wisdom, highlighted in the same study (Sum \& Leung, 2013) as being able to distinguish between good and evil. In addition, spirituality as an internal force also acts as a healing power for self (Chiu, 2000) and the source of support fostering inner peace and quietness through religious or cultural dimensions of practice (Yang et al., 2012).

\section{Category 3: A harmonious relationship}

Spirituality was also described as a harmonious connection (F101), manifested within the self (Chao et al., 2002) (F071), with significant others (Chiu, 2001) and nature (Chao et al., 2002), and resides in mysteries such as God, the spirit, or the soul. For example, a participant stated that she now had hope because she knew she could expect a serene afterlife in heaven (F006) (Mok et al., 2010).

Among the various relationship in Chinese understanding of spirituality. Relationship with self appears the most important. This is because many participants in the selected studies stated that the personal quality of being kind (Chao et al., 2002; Lin et al., 2012), diligent (Hsiao et al., 2011), tolerant (Hsiao et al., 2011) and having meaning and purpose of life for own development (Chiu, 2000) were essential when establishing a harmonious relationship with self. The ultimate aim of this relationship with self was achieved by gaining self-transcendence through helping others and self-cultivation (Chio et al., 2008) which are the important teachings in Chinse cultural values in Buddhism and Confucianism.

\section{Category 4: Suffering}

For some participants, spirituality was related to suffering. For example, one participant in Chio et al.'s (2008) study described spirituality as the physical torture of cancer which led to his or her pessimistic thoughts about wanting to die (F031). Another, in Yang et al.'s (2012), associated spirituality with mental

\section{Page 8 of 25}


illness, causing their sense of powerlessness (F021). Some explained their strategy in dealing with physical pain and suffering when explaining spirituality, such as drawing on Buddhist practice of chanting (Chiu, 2000), gaining support from family-friends and other cancer patients, and searching for meaning in life through religious or cultural explanations (Chio et al., 2008). Others laid out their expectations for companionship of children during health deterioration (Shih et al., 2009).

The above description shows that the Chinese understanding of spirituality as suffering is healthfocused, especially for physical illness. This may be because the selected studies were conducted in a health or nursing setting or because the other aspects of suffering in participants' life did not come into their focus when conducting the study. However, illness and physical discomfort are the major concerns in their understanding of spirituality. Chinese cultural values, such as Chinese philosophical explanations of suffering and filial support, were stressed during illness.

\section{Category 5: Traditional Chinese cultural values and Category 6: Religion}

Spirituality in the Chinese context has a constant focus on Chinese cultural values. For example, a participant explained their illness was due to the Ming (destiny) in Buddhism (Yang et al., 2012) (F020) and another related spirituality to Qi-Gong (Hsiao et al., 2011) (F011). Qi- Gong is an exercise of keeping healthy, founded on Daoism to keep the internal force flowing inside body in maintaining health.

Chinese spirituality also refers to religiosity. For example, participants 'expressed spirituality in terms of different religions' (Wong \& Yau, 2010 p.243). This was also stressed in Chiu's (2000) study, with participants consoling themselves in the belief of religion (F084), and another in Hsiao et al.'s (2011) demonstrating how spirituality was connected to the influence of religion upon their conscience (F016).

While Chinese understanding of spirituality is linked to cultural values and religiosity, the religious and cultural boundaries in the understanding of spirituality is obscure in Chinese culture, mainly because, as the review shows, the participants were not clear whether to classify Confucianism, Buddhism and Daoism as religion. This is particularly the case when comes to the concept Higher Beings. For example, in Mok et al.'s (2010) study, the authors interpreted God/Higher Power as religious elements by 
categorising these concepts in the sub-theme 'Having faith in God/higher power through religious beliefs and practices'. However, it is not known whether the participants were indicating God or Higher Beings in a religious or cultural sense. Although many authors, such as Mok et al. (2010), Yang et al.'s, (2012) and Chio et al.'s (2008) considered Confucianism, Buddhism and Daoism as religion, some studies such as Hsiao et al. (2011) and Chiu (2001) viewed these as cultural values, interpreting them as both religious and cultural philosophies. This indicates there is ambiguity regarding whether spirituality is cultural or religious connotation in Chinese understanding.

\section{Theme 2: Implementation of spiritual care}

\section{Category 1: Ways of spiritual care}

This category suggests there are different ways of providing spiritual care, including complementary therapy (F066), art (F067), restructuring life perspective (F083) and religious help (F065, F011). In Chiu's (2001) study, one participant explained that their source of spirituality was found in alternative therapies relating to their spiritual care. Another stressed the importance of art, prose and literature in spiritual care (F066).

Participants in Sum and Leung's (2013) study related spiritual care to physical, psychological, social and spiritual methods, illustrating that being physically healthy, having a positive attitude, communicating and sharing with others, and having religious belief and hope can help with good spiritual care. This suggests that in a Chinese environment it is comprehensive, integrating physical psychological social and spiritual aspects (Narayanasamy, 1999).

\section{Category 2: Barriers and benefits of spiritual care}

The barriers and benefits of implementing spiritual care were outlined in Wong \& Yau's (2010) study.

For example, two participants indicated that spiritual care would increase their workload (F058) and they used the word 'burden' to describe their opinion on the difficulties they faced when carry out spiritual

\section{Page 10 of 25}


care (Wong \& Yau, 2010). Other barriers included insufficient knowledge and skills, lack of managerial support, inadequate workforce and resources, and cultural factors (F062). For example, Chinese people generally avoided discussions about death, and they were unlikely to discuss the meaning of life or death (Wong \& Yau, 2010).

However, some nurses suggested that spiritual care might offer benefits to patients and nurses (Wong \& Yau, 2010). This included improving patients' physical comfort when praying (F054), reducing their anxiety during meditation (F055) and enhancing nurses' autonomy through the provision of spiritual care. The barriers and benefits in providing spiritual care reveal something about the feasibility of putting different elements of spirituality into practice, for example, whether Chinese cultural customs regarding attitudes towards death and dying could be put into practice when people from Chinese backgrounds avoid facing these issues.

\section{Category 3: Factors influencing spirituality and spiritual care}

Among the seven quantitative studies, six presented demographic factors influencing on nurses'

understanding of spirituality and the practice of spiritual care (Chan, 2010; Chung et al., 2007; Wong et al., 2008; Yang, 2006; Yang \& Wu, 2009; Yang \& Mao, 2007). Among these, religious belief was the most frequently presented factor in terms of spiritual care (F122, F128, F132, F135), with one study (Chung et al., 2007) (F125) revealing a negative relationship $(\mathrm{p}<0.001)$ and the other five a positive relationship $(\mathrm{p}<0.001)$. A different relationship between other demographic variables and spirituality and spiritual care were also presented in the other five studies (Chan, 2010; Wong et al., 2008; Yang, 2006; Yang \& Wu, 2009; Yang \& Mao, 2007). For example, Chan's (2010) (F122) study revealed that marital status was significantly related to nurses' understanding and practice of spiritual care, with married individuals having a higher score than single ones. By contrast, four studies (Chung et al., 2007; Yang, 2006; Yang \& Wu, 2009; Yang \& Mao, 2007) showed that marital status was not significantly related to nurses' practice of spiritual care and understanding of spirituality.

\section{Page 11 of 25}


One study (Chan et al., 2006) did not clarify whether there was relationship between demographic factors and spirituality/spiritual care. However, religious factor in this study may influence nurse's understanding of spirituality and spiritual care because it is a key characteristic informing the sub-groups of nurses (clusters) based on the similarity of the nurses' responses to the understanding of spirituality and practice of spiritual care questionnaire. Although there was no consensus regarding demographic factors influencing nurses' understanding of spirituality and the practice of spiritual care overall Chinese culture, their impact on spirituality and spiritual care may be relevant in local or institutional culture.

'Other factors' were items in the questionnaires and study design relevant to an understanding of spirituality and spiritual care. The 'self' (Chung et al., 2007), 'childhood spirituality' (Yang, 2006), and 'social systems' (Yang \& Wu, 2009) were all factors influencing nurses' spirituality and spiritual care. As these 'other factors' were dependent on the study design, they were very broad and included personal, organisational and other cultural settings in different regions or countries (Lucchetti et al., 2016; van Leeuwen, Tiesinga, Post, \& Jochemsen, 2006).

\section{Discussion}

Participants in the studies related their understanding of spirituality and spiritual care to an internal force, describing it as an integral part of humans which may manifest as inner energy from deep within the person. It may provide inner wisdom, enabling the person to distinguish between good and evil, and it may be a force for healing and recovery or a supporting resource. The Western healthcare literature also supports this premise of spirituality, using similar terms such as sustaining power (Murray, Zentner, \& Yakimo, 2009) and strength (Narayanasamy, 1999) to indicate that spirituality is a driving force.

However, the Chinese understanding integrates both the entity and internal force of human biology with spirituality, with an emphasis on the latter. This integration reflects their understanding of the jing, $Q i$, shen (精气神) where is rooted in the cultural values of Daoism and Traditional Chinese Medicine (TCM) in which, jing (精) is the essence and source of life, $Q i$ (气) is the vital energy of the body, and shen (神) is the vitality behind jing and $Q i$ (Li \& Shang, 2014). The jing, $Q i$, and shen are usually used together as a

\section{Page 12 of 25}


phrase in Chinese culture and TCM to demonstrate things related to essence, force and vitality. Thus, the term spirituality, which is jingshen in Chinese (combined from jing and shen), has the meaning of an essence, force and vibrancy in the human body. The integration of jing, Qi, shen into the understanding of spirituality demonstrates the importance of spiritual care, where $Q i$ is evident.

There is inconsistency in classifying Confucianism, Buddhism and Daoism into the religious or cultural domain, particularly for the concept Higher Beings. In Western culture, religion is defined as a formal organised system, associated with a Higher Being, rituals and beliefs (MacKinlay, 2006; McManus, 2006). Jacques (2012) therefore argues that Confucianism, Buddhism and Daoism do not qualify as religions because they are not organised and formal. However, this is complicated when participants interpret their understanding of God/Higher Beings as either religious or cultural when referring to spirituality in a Chinese culture.

Healthcare professionals therefore need to understand whether individuals from a Chinese background are referring to spirituality and Higher Being(s) in a religious or cultural sense. Participants may be sensitive to how spiritual care is implemented which will have implications for clinical practice. For PCB who claim a religious affiliation, this may make it more straightforward when assessing and implementing religious/spiritual care. Their beliefs may be expressed more freely which will help direct support and related spiritual activities, so the individual feels their values are understood and respected. Conversely, for individuals who indicates belief in a Higher Being(s) based on cultural customs, further exploration may be required to assess the appropriate level of support. Irrespective of whether PCB relate to Higher Being(s) in a religious or cultural sense, this area should be managed sensitively to avoid them feeling misunderstood or that their religious/spiritual beliefs have not been fully respected.

Participants in the Chinese studies related spirituality and spiritual care to their experiences of illness, possibly because it was their focus when the interviews were conducted. It suggests that awareness of spirituality is often raised during times of crisis or illness (Murray \& Zentner, 1989). A focus on physical problems during difficult times of illness reflects a generic understanding of spirituality

\section{Page 13 of 25}


as the reality that is important to participants (Swinton, 2010). It is therefore helpful for healthcare professionals to focus on the illness when implementing spiritual care.

When facing illness or crisis, relationships with the family and Chinese culture are important for people from Chinese backgrounds (Weathers et al., 2015) because they gain strength from these connections. For them, Chinese cultural and religious customs and values are important to help explain suffering and offer a way to cope with it. They also provide a foundation through which transcendence may be achieved, providing a new way of finding meaning and purpose in life. The importance of cultural values in spirituality is consistent with Western understanding since spirituality is expressed belief values, tradition (Puchalski et al., 2014). Therefore, nurses and other healthcare professionals from different cultures need to understand these values to grasp PCB's perspective of suffering and offer appropriate culturally sensitive spiritual care.

\section{Limitations}

This review explored studies conducted only in English and Chinese, and excluding grey literature. However, it provides a unique understanding of spirituality and spiritual care from Chinese cultural perspectives, which could help nursing and healthcare professionals to provide culturally sensitive spiritual care to PCB.

\section{Conclusion}

This scoping review synthesised the current Chinese understandings of spirituality and spiritual care, revealing a focus on the internal force $Q i$ and suffering during illness. Thus, the nurses' priority in spiritual care for PCB should be to relieve pain and suffering. Also, $Q i$-related activities, such as $Q i-$ Kong and Chinese medicine could be incorporated into the spiritual care provided for this group.

The findings also revealed a gap in the body of knowledge with respect to spirituality and spiritual care: whether the concept of spirituality and 'Higher Being(s)' are raised in a cultural or religious sense in PCB's understanding. Future research could therefore explore the spirituality and spiritual care in

\section{Page 14 of 25}


relation to cultural or religious understandings and Higher Beings are associated with culture or religion.

It could also include grey literature and articles in other languages to provide a wider understanding of the area.

The nurses' demographic factors impact differently on their understanding of among different regions or intuitions. Therefore, practice of spiritual care may need to be specified in terms of nurses' characteristics. For example, if the nurse religious factor is important in their practice of spiritual care in a certain hospital, nurses with religion may need to be chosen for the implementation of spiritual care.

\section{References}

Arksey, H., \& O'Malley, L. (2005). Scoping studies: towards a methodological framework. International Journal of Social Research Methodology, 8(1), 19-32. doi:10.1080/1364557032000119616

Author. (2019). Meaning and experiences of spirituality and spiritual care among people from Chinese backgrounds living in England: a grounded theory investigation. $\mathrm{PhD}$ thesis, Staffordshire University, Stoke-on-Trent.

Carson, V. B., \& Stoll, R. (2009). Spirituality defining the indefinable and reviewing its place in nursing. In V. B. Carson \& H. G. Koenig (Eds.), Spiritual Dimensions of Nursing Practice (Revised ed.). West Conshohocken: Templeton Press.

Chan, M. F. (2010). Factors affecting nursing staff in practising spiritual care. Journal of Clinical Nursing, 19(15-16), 2128-2136. doi:10.1111/j.1365-2702.2008.02690.x

Chan, M. F., Chung, L. Y. F., Lee, A. S. C., Wong, W. K., Lee, G. S. C., Lau, C. Y., . . Ng, J. W. S. (2006). Investigating spiritual care perceptions and practice patterns in Hong Kong nurses: results of a cluster analysis. Nurse Education Today, 26(2), 139-150.

Chao, C. S., Chen, C. H., \& Yen, M. (2002). The essence of spirituality of terminally ill patients. Journal of Nursing Research, 10(4), 237-245.

Chio, C., Shih, F., Chiou, J., Lin, H., Hsiao, F., \& Chen, Y. (2008). The lived experiences of spiritual suffering and the healing process among Taiwanese patients with terminal cancer. Journal of Clinical Nursing, 17(6), 735-743. doi:10.1111/j.1365-2702.2006.01854.x

Chiu, L. (2000). Lived experience of spirituality in Taiwanese women with breast cancer...including commentary by Clark MB and Daroszewski EB with author response. Western Journal of Nursing Research, 22(1), 29-53.

Chiu, L. (2001). Spiritual resources of Chinese immigrants with breast cancer in the USA. International Journal of Nursing Studies, 38(2), 175-184.

Chung, L. Y. F., Wong, F. K. Y., \& Chan, M. F. (2007). Relationship of nurses' spirituality to their understanding and practice of spiritual care. Journal of Advanced Nursing, 58(2), 158-170. doi:10.1111/j.1365-2648.2007.04225.x

Cockell, N., \& McSherry, W. (2012). Spiritual care in nursing: an overview of published international research. Journal of Nursing Management, 20(8), 958-969. doi:10.1111/j.1365-2834.2012.01450.x

Colquhoun, H. L., Levac, D., O'Brien, K. K., Straus, S., Tricco, A. C., Perrier, L., . . Moher, D. (2014). Scoping reviews: Time for clarity in definition, methods, and reporting. Journal of Clinical Epidemiology, 67(12), 1291-1294. doi:10.1016/j.jclinepi.2014.03.013

\section{Page $\mathbf{1 5}$ of $\mathbf{2 5}$}


Critical Appraisal Skills Programme (CASP). (2013). Qualitative research checklist: 10 questions to help you make sense of qualitative research. Retrieved from http://media.wix.com/ugd/dded87 29c5b002d99342f788c6ac670e49f274.pdf

Hsiao, S. M., Gau, M. L., Ingleton, C., Ryan, T., \& Shih, F. J. (2011). An exploration of spiritual needs of Taiwanese patients with advanced cancer during the therapeutic processes. Journal of Clinical Nursing, 20(7-8), 950-959. doi:http://dx.doi.org/10.1111/j.1365-2702.2010.03278.x

International Council of Nurses (ICN). (2012). The ICN code of ethics for nurses (Revised). Retrieved from http://www.icn.ch/who-we-are/code-of-ethics-for-nurses/

Jacques, M. (2012). When China rules the world: the end of the Western world and the birth of a new global order (Vol. 2nd). London: Penguin.

Joanna Briggs Institute (JBI). (2011). Joanna Briggs Institute reviewers' manual 2011. South Australia: The Joanna Briggs Institute.

Joanna Briggs Institute (JBI). (2014). Joanna Briggs Institute reviewers' manual 2014: Methodology for JBI mixed methods systematic reviews (Vol. 2015). The University of Adelaide, South Australia: The Joanna Briggs Institute.

Li, X., \& Shang, S. (2014). Fundamental nursing $[\square \square \square \square]$ (5th ed.). Retrieved from http://www.zysj.com.cn/lilunshuji/jichuhulixue/1009-3-1.html

Lin, H. J., Ma, W. F., Chen, Y. M., \& Chou, S. M. (2012). The Spiritual nature of emergency room nurses [Chinese]. Journal of Nursing \& Healthcare Research, 8(3), 223-231. doi:10.6225/JNHR.08.3.223

Lucchetti, G., Ramakrishnan, P., Karimah, A., Oliveira, G., Dias, A., Rane, A., . . Koenig, H. (2016). Spirituality, religiosity, and health: A comparison of physicians' attitudes in Brazil, India, and Indonesia. International Journal of Behavioral Medicine, 23(1), 63-70. doi:10.1007/s12529-0159491-1

MacKinlay, E. (2006). Spiritual growth and care in the fourth age of life. London and Philadelphia: Jessica Kingsley Publishers.

McManus, J. (2006). Spirituality and health. Nursing Management, 13(6), 24-27.

McSherry, W. (2007). The meaning of spirituality and spiritual care within nursing and healthcare practice: A study of the perceptions of health care professionals, patients and the public. London: Quay Books.

McSherry, W., \& Cash, K. (2004). The language of spirituality: An emerging taxonomy. International Journal of Nursing Studies, 41(2), 151-161.

Mok, E., Wong, F., \& Wong, D. (2010). The meaning of spirituality and spiritual care among the Hong Kong Chinese terminally ill. Journal of Advanced Nursing, 66(2), 360-370. doi:10.1111/j.13652648.2009.05193.x

Murray, R., \& Zentner, J. P. (1989). Nursing concepts for health promotion. London: Prentice Hall.

Murray, R., Zentner, J. P., \& Yakimo, R. (2009). Health promotion strategies through the life span (8th ed.). Upper Saddle River: Pearson Prentice Hall.

Narayanasamy, A. (1993). Nurses' awareness and educational preparation in meeting their patients' spiritual needs. Nurse Education Today, 13(3), 196-201.

Narayanasamy, A. (1999). A review of spirituality as applied to nursing. International Journal of Nursing Studies, 36(2), 117-125. doi:http://dx.doi.org/10.1016/S0020-7489(99)00007-3

National Institute for Health and Excellence (NICE). (2009). Process and methods guides: Methods for the development of NICE public health guidance (3rd ed.). Retrieved from https://www.nice.org.uk/article/pmg4/resources/non-guidance-methods-for-the-development-of-nicepublic-health-guidance-third-edition-pdf

Puchalski, C. M., Vitillo, R. J., Hull, S. K., \& Reller, N. (2014). Improving the spiritual dimension of whole person care: Reaching national and international consensus. Journal of Palliative Medicine, $17(6), 642-656$.

\section{Page 16 of $\mathbf{2 5}$}


Shih, F., Lin, H., Gau, M., Chen, C., Hsiao, S., Shih, S., \& Sheu, S. (2009). Spiritual needs of Taiwan's older patients with terminal cancer. Oncology Nursing Forum, 36(1), E31-38. doi:10.1188/09.ONF.E31-E38

Sum, F., \& Leung, L. (2013). The perception of healthy spirit of a group of student enrolled nurses in Hong Kong [Chinese]. Macau Journal of Nursing, 12(1), 30-34.

Swinton, J. (2010). The meaning of spirituality: A multiple-perspective approach to the 'spiritual'. In W. McSherry \& L. Ross (Eds.), Spiritual Assessment in Healthcare Practice. GB: M\&K Update Ltd.

Tanyi, R. A. (2002). Towards clarification of the meaning of spirituality. Journal of Advanced Nursing, 39(5), 500-509. doi:10.1046/j.1365-2648.2002.02315.x

Tricco, A. C., Lillie, E., Zarin, W., O'Brien, K. K., Colquhoun, H., Levac, D., . . Straus, S. E. (2018). PRISMA extension for scoping reviews (PRISMA-ScR): Checklist and explanation. Ann Intern Med, 169(7), 467-473. doi:10.7326/m18-0850

van Leeuwen, R., Tiesinga, L. J., Post, D., \& Jochemsen, H. (2006). Spiritual care: Implications for nurses' professional responsibility. Journal of Clinical Nursing, 15(7), 875-884. doi:10.1111/j.13652702.2006.01615.x

Weathers, E., McCarthy, G., \& Coffey, A. (2015). Concept analysis of spirituality: An evolutionary approach. Nursing Forum, 51 (2). p. 79-96. doi:10.1111/nuf.12128

Wong, K., Lee, L. Y. K., \& Lee, J. K. L. (2008). Hong Kong enrolled nurses' perceptions of spirituality and spiritual care. International Nursing Review, 55(3), 333-340.

Wong, K. F., \& Yau, S. Y. (2010). Nurses' experiences in spirituality and spiritual care in Hong Kong. Applied Nursing Research, 23(4), 242-244. doi:10.1016/j.apnr.2008.10.002

World Health Organization (WHO). (2013). Palliative care. Retrieved from http://www.who.int/cancer/palliative/en/

Yang, C., Narayanasamy, A., \& Chang, S. L. (2012). Transcultural spirituality: The spiritual journey of hospitalized patients with schizophrenia in Taiwan. Journal of Advanced Nursing, 68(2), 358-367. doi:http://dx.doi.org/10.1111/j.1365-2648.2011.05747.x

Yang, K. (2006). The spiritual intelligence of nurses in Taiwan. Journal of Nursing Research (Taiwan Nurses Association), 14(1), 24-34.

Yang, K., \& Wu, X. (2009). Spiritual intelligence of nurses in two Chinese social systems: A crosssectional comparison study. Journal of Nursing Research (Taiwan Nurses Association), 17(3), 189198. doi:10.1097/JNR.0b013e3181b2556c

Yang, K., \& Mao, X. Y. (2007). A study of nurses' spiritual intelligence: A cross-sectional questionnaire survey. International Journal of Nursing Studies, 44(6), 999-1010. doi:http://dx.doi.org/10.1016/j.ijnurstu.2006.03.004 
Table 1 Search strategy ${ }^{\mathrm{a}}$

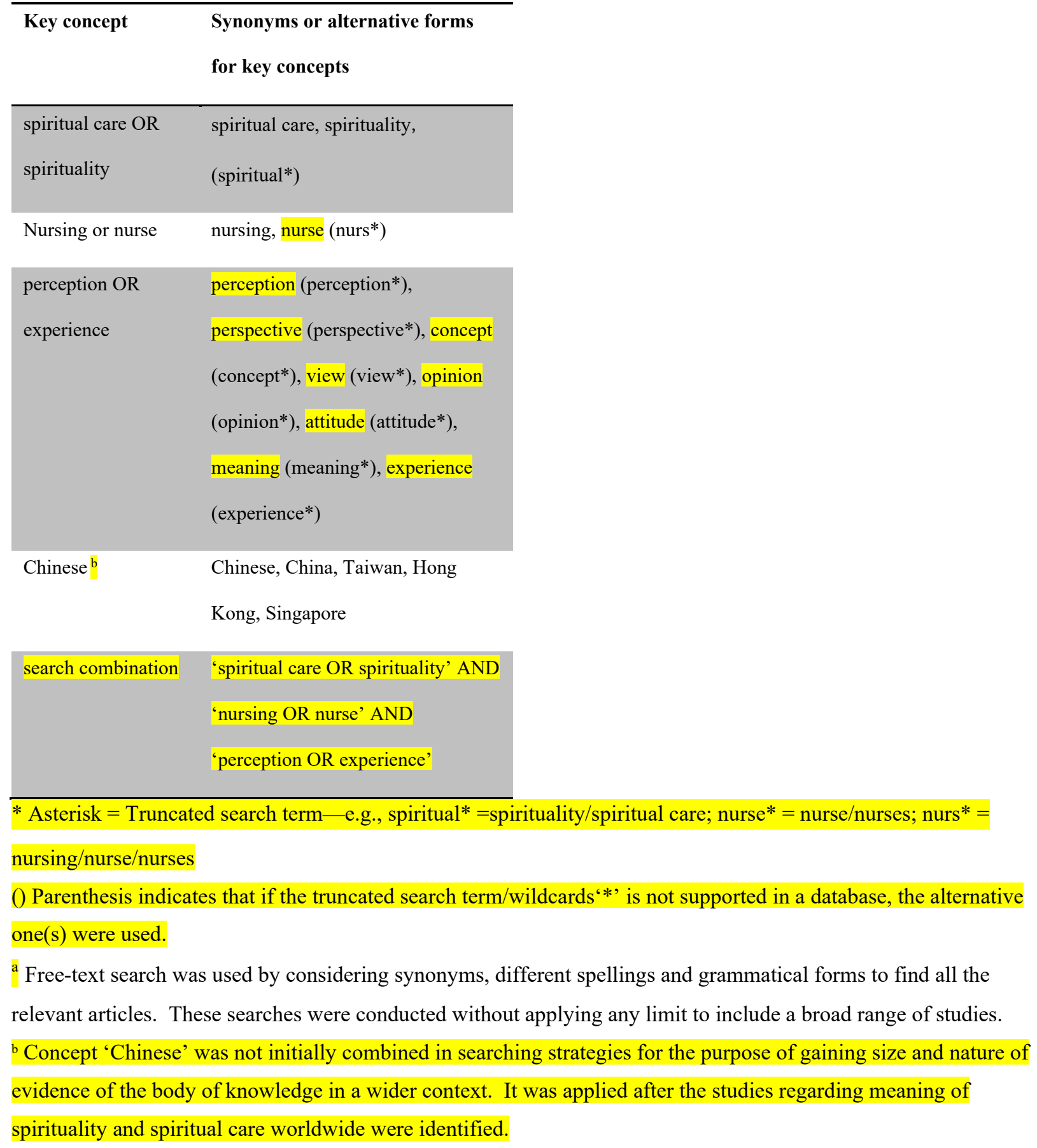

\section{Page 18 of 25}


Table 2 Inclusion and exclusion criteria

\begin{tabular}{|c|c|c|}
\hline & Inclusion criteria & Exclusion criteria \\
\hline 1 & Empirical studies & Review, discussion papers \\
\hline 2 & $\begin{array}{l}\text { Studies that focus on the perceptions of } \\
\text { spirituality and spiritual care }\end{array}$ & $\begin{array}{l}\text { Studies mainly addressing other issues, such } \\
\text { as quality of life, pastoral care, hope and } \\
\text { compassionate care. }\end{array}$ \\
\hline 4 & $\begin{array}{l}\text { Journal articles, dissertations, studies } \\
\text { obtainable on-line, or hard copy in the library, } \\
\text { or inter-library loan, or contacting authors }\end{array}$ & $\begin{array}{l}\text { Textbooks, book chapters and other forms of } \\
\text { publication }\end{array}$ \\
\hline 5 & Studies published in English and Chinese & Studies published in other languages \\
\hline 6 & $\begin{array}{l}\text { Studies with an abstract and studies without } \\
\text { abstract but full text that can be accessed on- } \\
\text { line or through inter-library loan }\end{array}$ & $\begin{array}{l}\text { Studies without an abstract and full text not } \\
\text { obtainable, which are outside of inter-library } \\
\text { loan or not available by contacting authors }\end{array}$ \\
\hline 7 & $\begin{array}{l}\text { From when the first empirical study was } \\
\text { published to December } 2018 \text { when this review } \\
\text { was drafted for publishing }\end{array}$ & \\
\hline 8 & $\begin{array}{l}\text { Studies conducted in a Chinese setting, such as } \\
\text { Taiwan, Hong Kong, a Chinese community in } \\
\text { foreign countries }\end{array}$ & $\begin{array}{l}\text { Studies conducted outside of a Chinese } \\
\text { setting }\end{array}$ \\
\hline
\end{tabular}


Table 3 Findings of literature review

\begin{tabular}{|c|c|c|}
\hline $\begin{array}{l}\text { Theme } \\
\text { (Level 3) }\end{array}$ & $\begin{array}{l}\text { Category } \\
\text { (Level 2) }\end{array}$ & $\begin{array}{l}\text { Findings (themes, subthemes, and main points extracted from the included studies) } \\
\text { (Level 1) }\end{array}$ \\
\hline \multirow[t]{6}{*}{ Meaning of spirituality } & 1. Characteristics of spirituality & $\begin{array}{l}\text { F110 Spirituality is an abstract state which is difficult to articulate } \\
\text { F093 They also pointed out that spirituality is complicated }\end{array}$ \\
\hline & 2. Internal force & $\begin{array}{l}\text { F109 Spirituality is a true and existing spiritual power } \\
\text { F091 Nursing students described that spirituality is a person's inner spiritual world }\end{array}$ \\
\hline & 3. A harmonious relationship & $\begin{array}{l}\text { F101 Harmony: healthy spirituality is harmony } \\
\text { F006 Having faith in God or a higher power } \\
\text { F071 Inner peace: spirituality is negotiating conflicts for self-reconciliation }\end{array}$ \\
\hline & 4. Suffering & $\begin{array}{l}\text { F021 Limited autonomy, self-actualisation and dignity: limited autonomy, self-actualisation and dignity leads to a sense of } \\
\text { powerless } \\
\text { F031 Feeling distressed because of physical pain }\end{array}$ \\
\hline & 5. Traditional Chinese cultural values & $\begin{array}{l}\text { F011 Seeking complementary alternative therapy and religious help } \\
\text { F020 Taiwanese or Chinese ideology: using Taiwanese or Chinese ideology to explain significant events in life }\end{array}$ \\
\hline & 6. Religion & $\begin{array}{l}\text { F084 Religion } \\
\text { F016 Follow God's or Heaven's will }\end{array}$ \\
\hline $\begin{array}{l}\text { Implementation of } \\
\text { spiritual care }\end{array}$ & 1. Ways of spiritual care & $\begin{array}{l}\text { F011 Seeking complementary alternative therapy and religious help } \\
\text { F065 Spiritual resource: religion } \\
\text { F066 Spiritual resource: alternative therapies ba guo lian jun } \\
\text { F067 Spiritual resource: art, prose and literature } \\
\text { F083 Finding alternative way of life: restructuring life perspective }\end{array}$ \\
\hline
\end{tabular}

Page 20 of $\mathbf{2 5}$ 


$\begin{array}{ll}\text { 2. Barriers and benefits of spiritual } & \text { F058 Difficulties in applying spiritual care: spiritual care increases workload } \\ \text { care } & \text { F062 Cultural factors inhibit spiritual care } \\ & \text { F054 Benefits of applying spiritual care: spiritual care improves physical comfort } \\ & \text { F055 Spiritual care improves psychosocial comfort } \\ \text { 3. Factors influencing spirituality and } & \text { F122 Factors associated with nurses' level of practising spiritual care } \\ \text { spiritual care (quantitative synthesis) } & \text { F125 Relationship of demographic variables with spirituality, understanding and practice of spiritual care } \\ & \text { F128 The effect of demographic characteristics on spiritual intelligence in nurses } \\ & \text { F132 Effect of religions on spiritual intelligence } \\ & \text { F135 Nurses' spiritual intelligence in relation to demographics }\end{array}$

$\mathrm{F}=$ findings; number $=$ sequence of an extracted finding

Page 21 of $\mathbf{2 5}$ 
Table 4 Characteristics of included studies

\begin{tabular}{|c|c|c|c|c|c|c|c|}
\hline Author and Year & Methodology & Focus & Geographical area & Language & Sample & Participant & Conclusion \\
\hline (Chiu, 2000) & $\begin{array}{l}\text { Qualitative, } \\
\text { phenomenology }\end{array}$ & $\begin{array}{l}\text { Explore lived experience of spirituality in Taiwanese } \\
\text { women with breast cancer. }\end{array}$ & Taiwan & English & 15 & Patients & Cultural spiritual care is needed. \\
\hline (Chiu, 2001) & $\begin{array}{l}\text { Qualitative, ethnography } \\
\text { and phenomenology }\end{array}$ & $\begin{array}{l}\text { Investigate cultural-spiritual resources that are available } \\
\text { to Chinese immigrants with breast cancer in the US. }\end{array}$ & USA & English & 15 & Patients & $\begin{array}{l}\text { Spiritual resources are } \\
\text { multidimensional. }\end{array}$ \\
\hline (Chao et al., 2002) & Qualitative study & Investigate terminally patients' spirituality. & Taiwan & English & 6 & Patients & Spirituality is addressed. \\
\hline $\begin{array}{l}\text { (Chan et al., } \\
\text { 2006) }\end{array}$ & Quantitative & $\begin{array}{l}\text { Address the paucity of available information on nurses' } \\
\text { spiritual care }\end{array}$ & $\begin{array}{l}\text { Hong Kong, } \\
\text { University }\end{array}$ & English & 193 & $\begin{array}{l}\text { Part-time } \\
\text { nurses }\end{array}$ & $\begin{array}{l}\text { Nurses lack spiritual care for } \\
\text { patient. }\end{array}$ \\
\hline (Yang, 2006) & $\begin{array}{l}\text { Cross-sectional } \\
\text { descriptive }\end{array}$ & $\begin{array}{l}\text { Examine the relationship between nurses' demographic } \\
\text { characteristics and spiritual intelligence }\end{array}$ & $\begin{array}{l}\text { Taipei, Taiwan, } \\
\text { A conference }\end{array}$ & English & 299 & Nurses & $\begin{array}{l}\text { Understanding nurses' spiritual } \\
\text { intelligence. }\end{array}$ \\
\hline $\begin{array}{l}\text { (Chung et al., } \\
\text { 2007) }\end{array}$ & Correlational design & $\begin{array}{l}\text { Examine the relationship of nurses' spirituality to their } \\
\text { understanding and practice of spiritual care. }\end{array}$ & $\begin{array}{l}\text { Hong Kong, } \\
\text { University } \\
\text { programme }\end{array}$ & English & 61 & $\begin{array}{l}\text { Nurse } \\
\text { students }\end{array}$ & $\begin{array}{l}\text { Nurses' demographics (except } \\
\text { religion) are not significantly } \\
\text { related to spiritual care. }\end{array}$ \\
\hline $\begin{array}{l}\text { (Yang \& Mao, } \\
\text { 2007) }\end{array}$ & $\begin{array}{l}\text { Cross-sectional } \\
\text { questionnaire survey }\end{array}$ & $\begin{array}{l}\text { Explore the profile of spiritual intelligence among } \\
\text { nurses and examine the effect of religions on nurses' } \\
\text { spiritual intelligence in China. }\end{array}$ & $\begin{array}{l}\text { Mainland } \\
\text { China. } \\
\text { A conference }\end{array}$ & English & 130 & Nurses & $\begin{array}{l}\text { Understanding nurses' spiritual } \\
\text { intelligence }\end{array}$ \\
\hline $\begin{array}{l}\text { (Chio et al., } \\
\text { 2008) }\end{array}$ & $\begin{array}{l}\text { Qualitative, } \\
\text { phenomenology }\end{array}$ & $\begin{array}{l}\text { Explore the lived experiences of spiritual suffering and } \\
\text { the change mechanism in healing processes among } \\
\text { Taiwanese patients with terminal cancer. }\end{array}$ & Taiwan & English & 21 & Patients & Patients need spiritual care. \\
\hline $\begin{array}{l}\text { (Wong et al., } \\
\text { 2008) }\end{array}$ & Cross-sectional design & $\begin{array}{l}\text { Explore Hong Kong nurses' perceptions of spirituality } \\
\text { and spiritual care; investigate the relationship between } \\
\text { their perceptions and their demographic characteristics. }\end{array}$ & $\begin{array}{l}\text { Hong Kong, } \\
\text { University } \\
\text { programme }\end{array}$ & English & 391 & $\begin{array}{l}\text { Enrolled } \\
\text { nurses }\end{array}$ & $\begin{array}{l}\text { Increasing nurses' spirituality in } \\
\text { education and continuing } \\
\text { development. }\end{array}$ \\
\hline
\end{tabular}




\begin{tabular}{|c|c|c|c|c|c|c|c|}
\hline $\begin{array}{l}\text { (Shih et al., } \\
\text { 2009) }\end{array}$ & $\begin{array}{l}\text { Qualitative, hermeneutic } \\
\text { inquiry }\end{array}$ & $\begin{array}{l}\text { Explore the patterns from the perspective of the older } \\
\text { patient with terminal cancer, focusing on spiritual need } \\
\text { and professional actions as spiritual care. }\end{array}$ & Taiwan & English & 35 & Patients & Patients have spiritual needs. \\
\hline $\begin{array}{l}\text { (Yang \& Wu, } \\
\text { 2009) }\end{array}$ & $\begin{array}{l}\text { Cross-sectional } \\
\text { inferential study }\end{array}$ & $\begin{array}{l}\text { Compare spiritual intelligence between nurses in two } \\
\text { different Chinese societies }\end{array}$ & $\begin{array}{l}\text { Mainland China } \\
\text { and Taiwan }\end{array}$ & English & 524 & Nurses & $\begin{array}{l}\text { Understanding nurses' spiritual } \\
\text { intelligence. }\end{array}$ \\
\hline (Chan, 2010) & $\begin{array}{l}\text { Quantitative, descriptive } \\
\text { inferential analysis }\end{array}$ & $\begin{array}{l}\text { Examine nurses' attitudes to practising spiritual care and } \\
\text { determine factors associated with these attitudes. }\end{array}$ & $\begin{array}{l}\text { Hong Kong, a } \\
\text { public hospital }\end{array}$ & English & 110 & Nurses & $\begin{array}{l}\text { Perception and practice of } \\
\text { spiritual care relate positively. }\end{array}$ \\
\hline $\begin{array}{l}\text { (Mok et al., } \\
\text { 2010) }\end{array}$ & $\begin{array}{l}\text { Qualitative, interpretive } \\
\text { phenomenology }\end{array}$ & $\begin{array}{l}\text { Explore the phenomenon of spirituality and spiritual } \\
\text { care among terminally ill Chinese patients. }\end{array}$ & Hong Kong & English & 15 & Patients & Patients need spiritual care. \\
\hline $\begin{array}{l}\text { (Wong \& Yau, } \\
\text { 2010) }\end{array}$ & $\begin{array}{l}\text { Qualitative, } \\
\text { phenomenological study }\end{array}$ & $\begin{array}{l}\text { Investigate the experiences of spirituality and spiritual } \\
\text { care in Hong Kong from the nurses' perspective. }\end{array}$ & Hong Kong & English & 10 & Nurses & $\begin{array}{l}\text { Barriers of providing spiritual } \\
\text { care. }\end{array}$ \\
\hline $\begin{array}{l}\text { (Hsiao et al., } \\
\text { 2011) }\end{array}$ & $\begin{array}{l}\text { Qualitative, explorative } \\
\text { qualitative enquiry }\end{array}$ & $\begin{array}{l}\text { Explores the spiritual needs of patients with advanced } \\
\text { cancer during their therapeutic process in Taiwan }\end{array}$ & Taiwan & English & 33 & Patients & Patients need religious support. \\
\hline $\begin{array}{l}\text { (Lin et al., } \\
\text { 2012) }\end{array}$ & $\begin{array}{l}\text { Descriptive qualitative } \\
\text { design }\end{array}$ & Explore perceptions of spirituality among ER nurses. & $\begin{array}{l}\text { A medical } \\
\text { centre Taiwan }\end{array}$ & Chinese & 15 & ER nurses & $\begin{array}{l}\text { ER nurses perceived spirituality } \\
\text { as an inner power. }\end{array}$ \\
\hline $\begin{array}{l}\text { (Yang et al., } \\
\text { 2012) }\end{array}$ & $\begin{array}{l}\text { Qualitative naturalistic } \\
\text { paradigm }\end{array}$ & $\begin{array}{l}\text { How hospitalisation and diagnosis of schizophrenia have } \\
\text { an impact on Taiwanese patients' spiritual life. }\end{array}$ & Taiwan & English & 22 & Patients & $\begin{array}{l}\text { Nurses need to provide spiritual } \\
\text { care. }\end{array}$ \\
\hline $\begin{array}{l}\text { (Sum \& Leung, } \\
\text { 2013) }\end{array}$ & Qualitative study & $\begin{array}{l}\text { Investigate nurse student's understanding of spirituality } \\
\text { and the learning needs for spiritual care. }\end{array}$ & Hong Kong & Chinese & 62 & $\begin{array}{l}\text { Nursing } \\
\text { students }\end{array}$ & $\begin{array}{l}\text { Taking care of self holistically } \\
\text { is crucial in life and work. }\end{array}$ \\
\hline
\end{tabular}


Figure 1 Summary of the search results in 2015

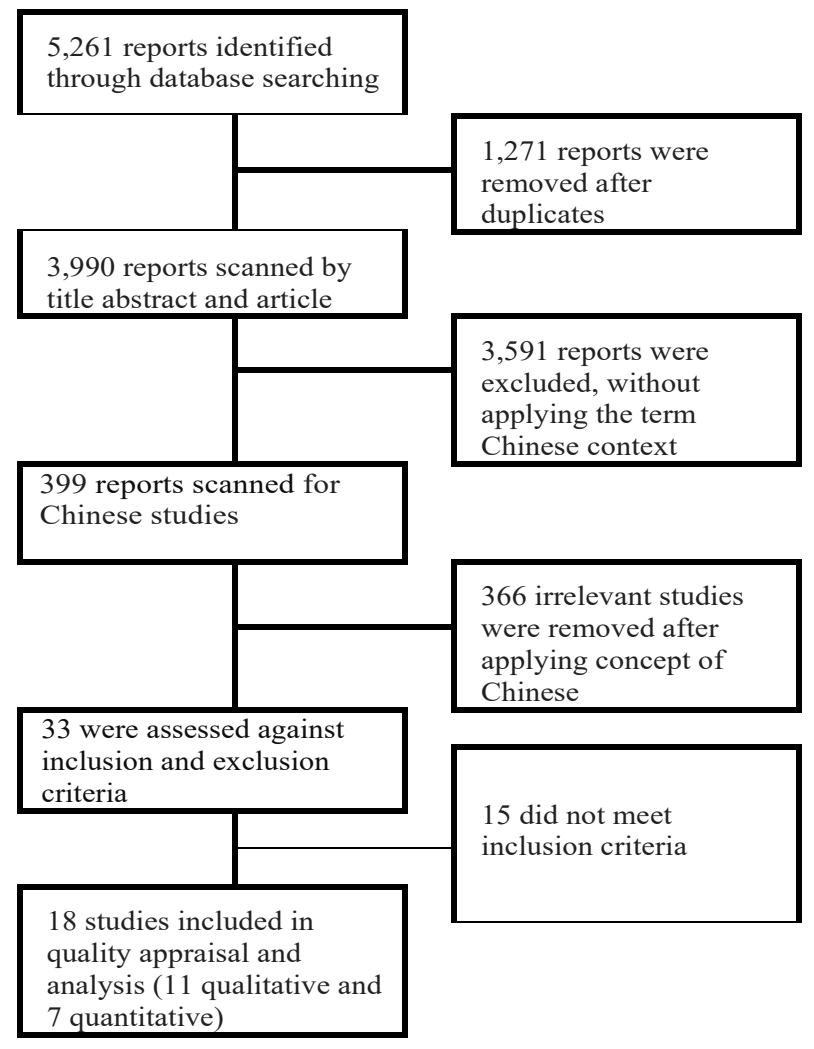


Page $\mathbf{2 5}$ of $\mathbf{2 5}$ 